\title{
Comparative analysis of domestic and feeder connected batteries for low voltage networks with high photovoltaic penetration.
}

\author{
George Hilton ${ }^{\mathrm{a}, *}$, Andrew Cruden ${ }^{\mathrm{a}}$, Jeremy Kent ${ }^{\mathrm{b}}$ \\ ${ }^{a}$ Faculty of Engineering and the Environment, University of Southampton, University Road, Southampton, SO17 1BJ, United Kingdom \\ ${ }^{b}$ Swanbarton Limited, The Old Cake House, The Dairy Farm, Pinkney, Wiltshire SN16 ONX, United Kingdom
}

\begin{abstract}
Excessive voltage and power flow issues associated with domestic solar power are threatening UK distribution system operation and the use of energy storage is one method proposed to mitigate these issues. In this study a data orientated approach was taken in order to simulate the effect of the location of the energy storage on the low voltage network. A number of small $(<15 \mathrm{kWh})$ domestic batteries were compared to a single larger $(>50 \mathrm{kWh})$ feeder connected battery in terms of their ability to shave load demand peaks, fill load demand valleys and counter voltage violations on a typical radial feeder system. To achieve this MatLab was used to create dispatch strategies for each battery and introduce them into an aggregated load, and OpenDSS was then used to model this scenario on a typical UK radial feeder based on the IEEE European Low Voltage Test Case.

It was found that the feeder connected battery was more successful at mitigating the thermal overload effects of distributed generation at the low voltage level. Domestic batteries offer ease of installation and consumer support, likely to make their utilisation increasingly inevitable. However, their exposure to domestic energy flows and focus on minimising grid import to the home led to a reduced network level impact. This work shows that a feeder connected battery can respond to the power flows of the aggregated load and thus provides a far more capable tool for reducing network peak loads and preventing feeder system export.
\end{abstract}

Keywords: Energy Storage, Solar PV, Voltage Violation, Thermal Overload, Distribution Network Modelling

प

\section{Introduction}

The UK has a requirement to reduce its carbon dioxide emissions by $80 \%$ by 2050 when compared to 1990 levels [1]. In order to achieve this ambitious target increasing numbers of renewable energy installations are being integrated into the national grid [2]. Renewable energy sources are, by their nature, intermittent and as such, a mechanism must be adopted to reduce mismatch between the demand and supply of electrical energy. Energy storage has been proposed as one method of achieving this where energy is stored when supply peaks and released when demand outstrips supply.

A recent concern within the UK has been electric network issues caused by domestic solar power, creating a demand for energy storage in two areas. Firstly, a homeowner with installed photovoltaic (PV) panels may want to reduce their reliance on supply from the grid and become self-sufficient. In this way the price paid for electricity can be minimised as well as reducing

\footnotetext{
${ }^{*}$ Corresponding author

Email addresses: g.hilton@soton. ac.uk (George Hilton), a.j.cruden@soton.ac.uk (Andrew Cruden), jez.kent@swanbarton.com (Jeremy Kent)

Abbreviations Voltage Unbalance Factor (VUF); After Diversity Maximum Demand (ADMD); Moving Average (MA); Moving Standard Deviation (MSTD)
}

the homeowner's environmental impact. An energy store must be employed to enable this since domestic electrical demand does not match well with solar irradiance [3]. Secondly, clustering of PV installations through community organisational effects and passive peer influence [4] leads to a high level of pressure on the grid infrastructure. This, without intervention, can lead to power flows and voltages straying from regulated limits [5]. As such, increased utilisation of energy storage in the distribution system can prevent or defer costly network upgrades needed due to these effects.

There was a large growth in solar PV installations in the UK during 2014, with overall PV capacity at the end of 2014 at 5095MW following a $79 \%$ annual increase [6]. This huge growth provided a significant stress to the ageing distribution system and caused a large change in the demands placed on the distribution infrastructure. This became an issue since the distribution network was not designed to enable distributed generation, where the component capacities for power flow are too low to be effective at high penetration levels, increasing the risk of circuit overload and voltage violation causing damage to components both within the distribution system and at the consumer end [7]. This continues to be a rapidly growing issue due to the prolific uptake of distributed generation and unlike most previous network issues it is not localised, rather it is affecting the entire system and a system wide approach must be adopted in order to mitigate it.

The constraints on distribution networks can be described by two key effects: 
1. Voltage Violation - Distributed generators can increase the voltage in the network they are connected to when they supply power. In order to prevent damage to network connected infrastructure the voltage must lie within set limits (+10\% -6\% for the LV Network) [8] and as such distributed generators can cause violation of these limits. In addition, voltage violation can be caused by voltage unbalance when a variation of greater than $2 \%$ is seen in the voltage [8].

2. Thermal Overload - The components of the distribution grid are required to transmit more power than they are designed for, hence, temperature increases and component failures can result, causing damage.

\section{Theory}

\subsection{Voltage Violation}

In order to achieve the stated Quality of Service Guaranteed Standards [9] the voltage on the system must not go above or below set limits [8]. These regulations are in place in order to prevent damage to network connected infrastructure.

Voltage rise at the connection point of a distributed generator is caused by power injection. For a radial feeder layout it can be expressed by Equation 1 [10].

$$
\Delta V \approx \frac{\left(P_{G}-P_{L}\right) R+\left(Q_{G}-Q_{L}\right) X}{V}
$$

$P_{G}$ and $Q_{G}$ are the real $(\mathrm{kW})$ and reactive $(\mathrm{kVA})$ powers of the distributed generator and $P_{L}$ and $Q_{L}$ are same for the line load. $R$ and $X$ are the line resistance and reactance (in Ohms) between the distributed generator and the substation and $V$ is the line voltage $(\mathrm{V})$ at the connection point. As such it can be seen that the problem of voltage rise is exacerbated by low load power on the feeder and high line resistance and reactance or line length.

Voltage unbalance is caused by non-equal loads on each of the phases in the distribution system. unbalance is one of the biggest problems facing LV networks [11]. It is stated in Engineering Recommendation P29 [12] that voltage unbalance be kept to within $2 \%$ for the entire network. This recommendation is in place to prevent damage to 3-phase equipment which can be caused by voltage unbalance [13]. Domestic PV installations, by their nature, provide a very inconsistent power injection onto a single phase in the network and as such greatly contribute to voltage unbalance [14]. It is possible that, within a feeder system, 70-90\% of the PV installations are on the same phase and in this situation a very large voltage unbalance would be expected to occur under conditions of domestic solar power export [11] and this effect is increased with distance from the substation. The definition of voltage unbalance is, however, not always consistent.

The voltage unbalance rate (VUR) is calculated as:

$$
V U R \%=\frac{\text { Maximum Voltage Deviation }}{\text { Average Voltage }} \times 100
$$

This definition is open to interpretation and, as shown by Pillay and Manyage [15], there are a number of different definitions depending on whether the average voltage is taken from the line or the phase. However, in both of these definitions only the magnitude of the unbalance is considered. The voltage unbalance factor (VUF) is the true definition of voltage unbalance and accounts for the change in phase angle, it is defined as:

$$
V U F \%=\frac{\text { negative sequence voltage component }}{\text { positive sequence voltage component }} \times 100(3)
$$

Voltage unbalance figures presented in this work are stated as VUF.

\subsection{Thermal Overload}

Thermal overload threatens the components of the distribution system through heating caused by the actual power exceeding equipment rated power levels.

Power transformers are the most expensive and important components in the electrical distribution network [16] and a power overload of this component can lead to multiple failure mechanisms [17]. Heating of the top oil in a power transformer, is often a precursor to failure. As heating above rated is proportional to the ratio of rated to actual load raised to the power of 1.4 [18], a failure from overheating becomes increasingly likely as the load increases.

The maximum current which overhead lines are permitted to carry is dependent on the overall heat transfer to the cable and the resistance as described in Equation 4 [14].

$$
I_{O L}=\sqrt{\frac{\Delta H}{R}}
$$

$I_{O L}$ is the current in the overhead line (A), $R$ is the resistance $(\Omega)$ of those lines and $\Delta H$ is the heat transfer from the cable to the surrounding environment (in Watts). Thus, it can be seen that, for increasing overload currents, reducing the resistance has a diminishing positive effect, and reducing the current has a squared effect on power loss and overload compared to resistance. Therefore, action to reduce the peak export current from distributed renewable generation with the inclusion of paired energy storage has a more positive effect on the network than peak shaving or demand side management at a distant point where cable connections are constrained.

With an after diversity maximum demand (ADMD) of roughly $2 \mathrm{~kW}$ (depending on location and inhabitants of homes) in the UK [19] the DNOs design and implement distribution networks assuming a peak power of $2 \mathrm{~kW}$ per home on the network. As such $I_{O L}$ (from equation 4 for the cables in the network and the rated power for the transformers are already set to these levels. The penetration of domestic solar and other distributed generation leads to immediate increases in the ADMD of the network. Rooftop PV arrays with capacity $0-4 \mathrm{~kW}$ account for $26 \%$ of UK solar deployment, of these, the average capacity is $2.92 \mathrm{kWp}$ [6]. However, the tariff structure in place until March 2016, encouraged PV arrays of $4 \mathrm{kWp}$ since these provide the largest return on investment [20]. As such, for a worst case scenario, it is assumed that a typical domestic PV array has a 
peak power of $4 \mathrm{~kW}$ (double the ADMD), and at high penetration levels where, due to the close geographical nature of most feeder systems, the arrays will be producing peak power at the same time, the export power (unless utilised to charge a battery) can quickly exceed the rated power of the feeder transformer or cause overheating of the distribution cables. Upgrading this infrastructure is a very costly and lengthy process and should be avoided where possible. As such, an energy store should be designed to reduce, as far as possible, the peak power exported by a feeder system.

\subsection{Domestic Battery Considerations}

It has been shown that the addition of a battery can produce a large reduction in the exported power expected, with an $87 \%$ reduction in exported energy when a $210 \mathrm{~V}, 500 \mathrm{Ah}$ battery is implemented with a $2.5 \mathrm{kWp}$ PV array in the example in [21]. Whilst this is a relatively large capacity battery as it is able to store 42 hours of peak PV generation, the study shows that a domestic battery allows a homeowner to move towards self-sufficiency and reduce reliance on fossil fuels. The introduction of the energy store can reduce the overall renewable curtailment and increase distribution system efficiency by reducing peak power flows and reducing voltage instabilities. The extent of this effect is, as yet, un-quantified [22].

The export peak reduction enabled by domestic batteries is dependent on the battery capacity when compared to the PV array power rating and the ratio of electrical energy used in the home and electrical energy generated by the PV array. A PV array which produces more power than the home uses necessarily leads to energy export regardless of the battery capacity. In addition a battery which has a very small capacity when compared to the PV array power will become fully charged in the morning and have very little effect on power export for the rest of the day.

There is significant, and growing, investment into the domestic battery market. Domestic batteries have proved very popular with homeowners with uptake for the new Tesla Powerwall, a 7/10kWh lithium-ion battery for the home, [23] far outstripping supply. In addition some governments are encouraging domestic energy storage uptake with subsidy programs. For example the German government introduced a program called Renewable Energies Storage in May 2013 [24]. This has the aim of promoting technological development of PV connected battery systems through grants and "soft loans" given to the owners of the battery systems. The main driver behind this subsidy is a policy decision in Germany to promote self-consumption of PV power as it is expected that growth in the domestic PV market will increase as costs become competitive without subsidy [25], in this way many of the adverse effects of high PV penetrations can be mitigated. Since the transmission grid in Germany often operates at capacity, it is suggested that selfconsumption of solar PV helps to increase predictability and stability of the German grid [26].

Despite this support and investment for domestic batteries, there is some evidence that their introduction will cause an increase in distribution system inefficiency when implemented without generation forecasting consideration [27]. This is due to the battery becoming fully charged prior to peak PV power, as such there will be no reduction in the peak power export but an increase in the rate of change of power export. This effect will be amplified due to the similar geographical locations and battery capacities seen on a feeder system and is a key factor which will be studied in this project. A counter to this is proposed by Marra et al. [28] where the dispatch of the battery is controlled according to an optimised power threshold, thus charging occurs during the peak of the solar irradiance rather than during the morning. This has the benefit of reducing peak exports, however this occurs at the expense of guaranteed maximum self consumption, since export of solar power in the morning may be allowed, but followed by a reduction in solar generation. This would lead to under-utilisation of the battery. The exact level of the optimised power threshold has a very large impact on the effectiveness of the battery; if it is set too high the battery will be under-utilised and self consumption will be reduced. As such it is anticipated that, for effective implementation, forecasting data [29] or a data connection to the DNO would be necessary.

[30] Suggests that overvoltages can be effectively controlled by energy storage within the home. The batteries are dispatched only when the injected power exceeds a specified limit. This is a very limited approach leading to low utilisation levels of the domestic battery and reduced scope for uptake due to minimal positive effects on self consumption levels. A similar approach is also suggested in reference [31]. Reducing overvoltages is necessary for improving voltage unbalance on the feeder since unequal numbers of PV installations regularly occur for each phase. However, this is not an optimal battery use strategy from the perspective of the homeowner hence they are likely to resist this.

The project "SoLa Bristol" run by Western Power Distribution consists of 26 homes, 11 substations, 5 schools and 1 office, with each property equipped with a DC-storage capability. The homes used are council owned and have PV installations of 1.5$2 \mathrm{kWp} .4 .8 \mathrm{kWh}$ valve regulated lead-acid batteries are installed into each property and these power a DC circuit [32]. The load on the DC circuit has a maximum power of $100 \mathrm{~W}$ and consists of LED lighting and USB sockets. Even with the quite small PV panels an average export of $30 \%$ of PV power to the grid was recorded. The installed battery cannot provide all the power demands of the household since the DC circuit cannot provide power for all the appliances in the home. This DC circuit in the home is always powered by either the batteries or the PV panels and as such the homeowner may preferentially use this source of energy over the traditional AC circuit. However, a limitation of this study is that all of the domestic load cannot be met by the internal battery and as such this does not accurately represent the Tesla Powerwall and other domestic batteries coming to the market. It was concluded that the demand patterns of homes with domestic energy stores must be very well known by the DNO as a high domestic load leads to very low evening demand reduction capability [33].

The literature suggests that if limits are placed on the utilisation of domestic batteries, or if complex algorithms are used to control their dispatch, they can have positive effects on the 
distribution network. However, the owners of these systems are likely to want maximum utilisation and self-consumption, since this is the driver for their purchase [34] and are therefore more likely to resist such measures. Therefore, a simple dispatch strategy is studied in this work as discussed in Section 3.1

\subsection{Feeder Connected Battery Considerations}

A feeder-connected energy store will be enabled to stabilise a much larger area of the grid than a single domestic battery. Valley filling and peak shaving can be achieved by charging and discharging the feeder-connected battery according to observed power flows on the entire feeder in order to achieve a feeder load which is more manageable for the distribution network. Since more reduction in the peak is allowed for a given capacity, peak shaving has been shown to be more effective with short peaks i.e. discharge durations of up to 1 hour [35]. Thus, for peak shaving characteristics a high power to capacity ratio for the battery is needed.

Valley filling is where an energy store acts as a load on the feeder, by increasing the minimum load experienced by the feeder system. This is particularly useful for feeder systems with high PV penetration since the network constraints, such a voltage excursions, occur at export or minimum power demand for the feeder system. Valley filling can help to mitigate voltage rise by increasing the load power. It has been shown that feeder-connected energy storage can reduce or eliminate voltage violations caused by distributed generators [36]. Indeed, a feeder-connected battery can be specifically designed to reduce voltage unbalance and prevent over-voltage [37].

Oudalov et al. [35] has shown a battery dispatch schedule utilising feeder voltage measurements to ensure voltage regulation was maintained. It was shown that feeder-connected energy storage can lead to greater utilisation of PV power output through charging during periods of light feeder load and high PV generation. Also, depending on battery location, there can be a significant reduction in voltage drop due to large load centres and it was suggested that a battery should be placed near these load centres in order to avoid this.

Additionally, an energy store has been used to control voltage unbalance levels to below $0.8 \%$ when the energy store was placed on the same phase as the distributed generator [38]. With high levels of PV penetration it is expected that distributed generation will be installed on each phase, as such, for effective voltage unbalance mitigation a 3 phase connection is required, or separate batteries on each phase. In addition, Saboori et al. showed that when constructing new distribution networks, including grid-connected energy storage reduces planning complexity and cost [39].

The "Zero Carbon Homes" demonstration project in Slough UK [40], utilised street level batteries in order to provide peak shaving capabilities of the real power flows of the feeder. Three $25 \mathrm{~kW} / 25 \mathrm{kWh}$ batteries were installed (one per phase) on a street supplying 10 homes having a PV penetration of $65 \mathrm{kWp}$. This lead to the main power flow constraint being evident during peak solar irradiance [40]. It was shown that the batteries provided very successful peak shaving capabilities under a number of operating conditions. The per-phase feeder demand could be successfully kept at $10 \mathrm{~kW}$ by use of the battery. In addition the battery system was controlled such that reverse power flow could be prevented and this was also demonstrated successfully. The use of three single phase batteries limited the project slightly due to an inability to balance phase loads, however, specific control is allowed per phase and as such if the target power flows are the same for each phase the result is a well balanced network [41]. This project showed a very successful implementation of a street level battery. However, the results are not applicable for wide scale use due to its implementation on the "Zero Carbon Homes" project. This is not a typical street within the UK (due to the $100 \%$ PV penetration). As such this project aims to simulate a more typical feeder system with a smaller range of PV penetrations, a larger number of homes and utilise smaller amounts of energy storage per home.

The feeder-connected energy store is successful in each of these referenced projects and, it is clear that the introduction of feeder-connected energy stores can act to significantly mitigate all the disadvantageous effects of distributed generators, such as domestic PV, on the distribution system across a range of dispatch strategies. In this work, however, the simulated feederconnected battery will act to simply perform load shifting in order to reduce feeder peak loads and exports.

\section{Material and Methods}

A $20 \%$ PV penetration has been suggested to be the level where voltage violations become an issue on the LV network [42]. As such, this value has been used throughout the authors simulations. The simulation of the effects of energy storage on an LV Network are carried out in Matlab and OpenDSS. The matlab model is used to assess real power flows according to aggregated demand and solar generation. A simple battery model is included in the matlab simulations. The round trip efficiency losses incured through use of the battery are not considered in this simulation. OpenDSS [43], an open source distribution network modelling tool, is then used to further investigate this modified demand to find effects associated with three phase supply and line parameters, such as losses and voltage unbalance.

\subsection{Domestic Battery Model}

It is assumed that the owner of a domestic battery will aim to achieve minimal grid import (indeed even full independence from the grid), hence a simple domestic dispatch model is implemented which ensures this through charge and discharge of the battery at the earliest possible opportunity [27].

Initially, the battery power is set to be the difference between the value of generated power from PV and domestic load demand for each iteration. If the resulting battery state of charge lies within allowable values (defined upper and lower state of charge limits) then the exchanged power with the grid is zero and the battery either absorbs all the excess power or provides the demand. If the battery is fully charged, then the battery power for that iteration is set to zero, and the power exchanged 
with the grid is set as the difference between generated power and load power. In the case of a fully discharged battery the same holds. There is no maximum power for the simulated battery, however, since the domestic load is always small this does not affect the results. This dispatch strategy is shown in Figure 1

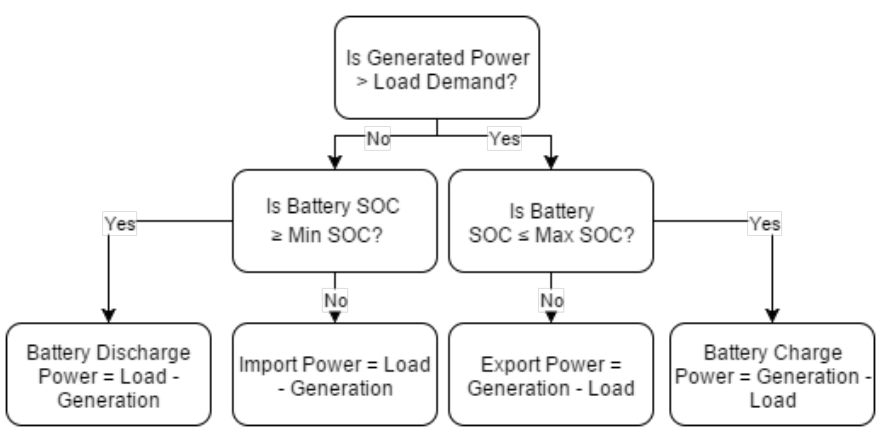

Figure 1: Dispatch strategy for a domestic battery solely aiming to maximise self-consumption.

This domestic battery model is applied to 11 of the 55 homes which also have PV generation, leading to a PV penetration level of $20 \%$. For the battery dispatch model, each home is simulated as a power demand array, for the homes with solar power and batteries, this array is then modified by the dispatch strategy discussed. The modified domestic load arrays are then aggregated with the unmodified arrays to show the feeder demand.

\subsection{Feeder Connected Battery Model}

The model of a feeder connected battery simulates a battery connected at a substation or feeder line. It is controlled to balance the aggregated feeder load. The first part of this simulation requires the determination of charging and discharging power levels of the aggregated demand, this cannot be set as a single value for the duration of the simulation due to the seasonal changes in feeder demand. Both the moving average (MA) and moving standard deviation (MSTD) are calculated for the demand over the preceding 24 hours, as such, the model can be used in real time (for control of the battery in-situ). Dispatch in either charge or discharge mode is controlled with Equation 5

$$
\text { Dispatch }=M A \pm(M S T D \times n)
$$

$n$ is the dispatch factor (in per unit standard deviation). A high dispatch factor will lead to lower utilisation of the battery and higher exports but increased likelihood of peak reduction. The dispatch factor should be optimised for the load shape in order to achieve full charge or discharge without feeder power levels straying above or below $M A \pm M S T D \times n$. The relationship between feeder demand, and charge and discharge levels is shown in Figure 2 where battery charging occurs when the feeder demand drops below the charge line, by a power equal to the difference between the charge level and feeder power demand. Equally, discharge occurs when the feeder power demand line goes above the discharge line. The feeder connected battery provides the power difference between the charge/discharge level and the feeder power demand given it can do so without exceeding SOC limits. The available power from the battery is assumed to be infinite, however, the dispatch factor is set such that this power does not exceed what a similar capacity Lithium-Ion battery would be capable of.

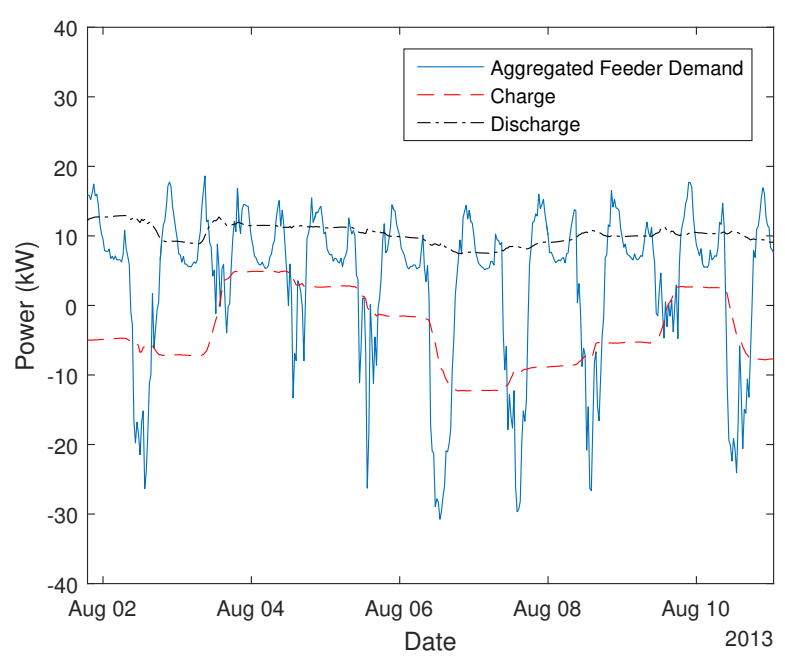

Figure 2: Charge and discharge levels, shown as moving average $\pm 0.75 \times$ moving standard deviation.

\subsection{OpenDSS Simulation}

For a simulation of the effects of the solar power and energy storage on the real and reactive power flows, and voltage levels the IEEE European Low Voltage Test Case, which is available with the OpenDSS package, was utilised. This comprises of 55 homes, each with a one phase connection in a generic distribution pattern to a $230 \mathrm{~V} / 11 \mathrm{kV}$ transformer, shown in Figure 3 . In an OpenDSS model buses are points of electrical connection and lines are modelled as resistive and inductive elements between buses. There are 906 buses and 905 lines in this model giving a realistic representation of a generic LV Network. The homes in this model are set as loads at the end of each small branch seen in Figure 3, where a positive load implies an energy flow from the network, and a negative value corresponds to an export to the network. The power factor for each home is set to 0.95 for non-solar homes, as the homes are users of energy; and 1 for solar homes, as when the homes are exporting, it is through the inverter and therefore no reactive power is exported onto the grid.

Data from the MatLab simulation was used to form the loadshapes within the OpenDSS model. Three simulations were undertaken as follows:

1. 55 homes taken from the Thames Valley Vision Project data [44] and simulated on the OpenDSS LV Network with the addition of $20 \%$ solar power penetration ( $4 \mathrm{kWp}$ per home) but no energy storage.

2. Using data from the matlab model, 11 homes, from the same 55, are assigned with both $4 \mathrm{kWp}$ solar PV and $7 \mathrm{kWh}$ domestic batteries. 


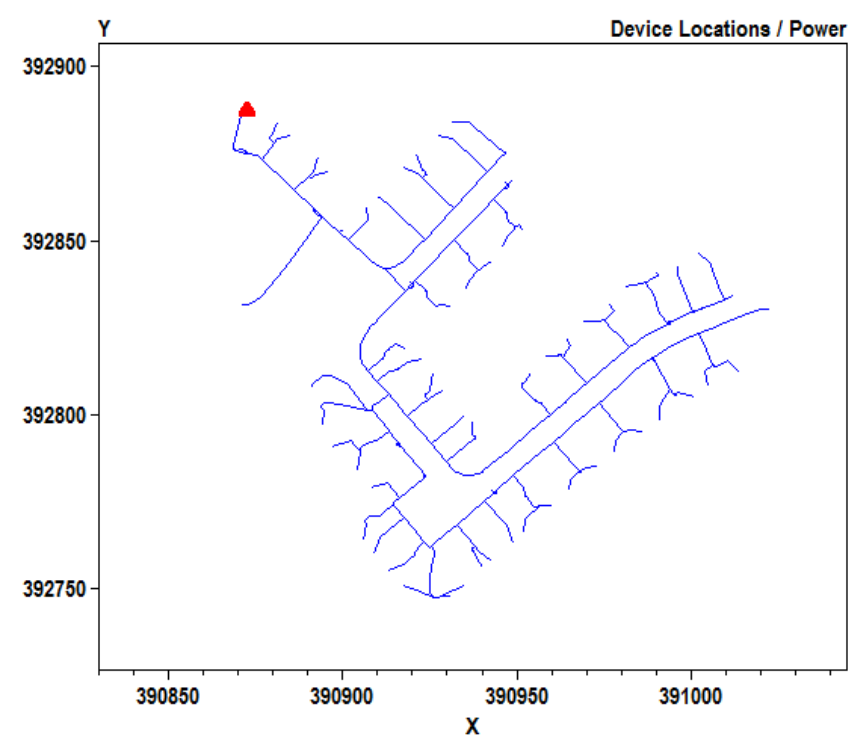

Figure 3: The topological view of bus orientation in the IEEE LV Test Case supplied with the OpenDSS package. X and Y axes are length coordinate system with units of meters. The red dot shows the position of the substation.

3. The same 11 homes are assigned with $4 \mathrm{kWp}$ solar PV, but without batteries. A single $77 \mathrm{kWh}$ battery is introduced at the substation. The dispatch of the battery is controlled in Matlab and is simply set as a load with positive and negative power flows at a power factor of 1 connected to the bus at the substation.

\subsection{Limitations and Assumptions}

A limitation exists through using existing data and adding energy storage and solar power to the demand profile since the behavior of the home inhabitants may be changed due to these additions. For example it is common for a homeownwer to shift some loads to the day time in order to improve domestic utilisation of solar power. This effect is not expressed here due to the nature of the data.

Only $4 \mathrm{kWp}$ solar arrays are studied here. Smaller arrays will lead to a more balanced load profile in the summer where solar panel energy equals load energy rather than exceeding it during summer months. A $4 \mathrm{kWp}$ panel was chosen since this size is the most popular due to the tariff structure in the UK [20], however there are many installations with a smaller power capacity.

Since the dispatch factor for the feeder connected battery does not change through the length of the simulation, optimal results are not achieved for feeder connected battery performance. The dispatch factor must be dynamic to respond to changes in load shape for optimal results. This was not the focus of this work and as such static dispatch factors were used. It should be emphasised that, in most cases, the performance of the feeder connected battery will be better than presented here due to this issue.

\section{Results and Discussion}

The base case for the model is a feeder system of 55 homes presented as the IEEE European LV Test Case. Data from the Thames Valley Vision project [44] was used as the loads for each home. This data has a resolution of 30 minutes and uses data from 220 homes in a similar geographical area of London over the period of one year. There is a significant seasonal pattern in the peak energy demand, with winter demand peaks of $\sim 35 \mathrm{~kW}$ and summer demand peaks of $\sim 20 \mathrm{~kW}$. However, the minimum demand does not vary significantly throughout the year.

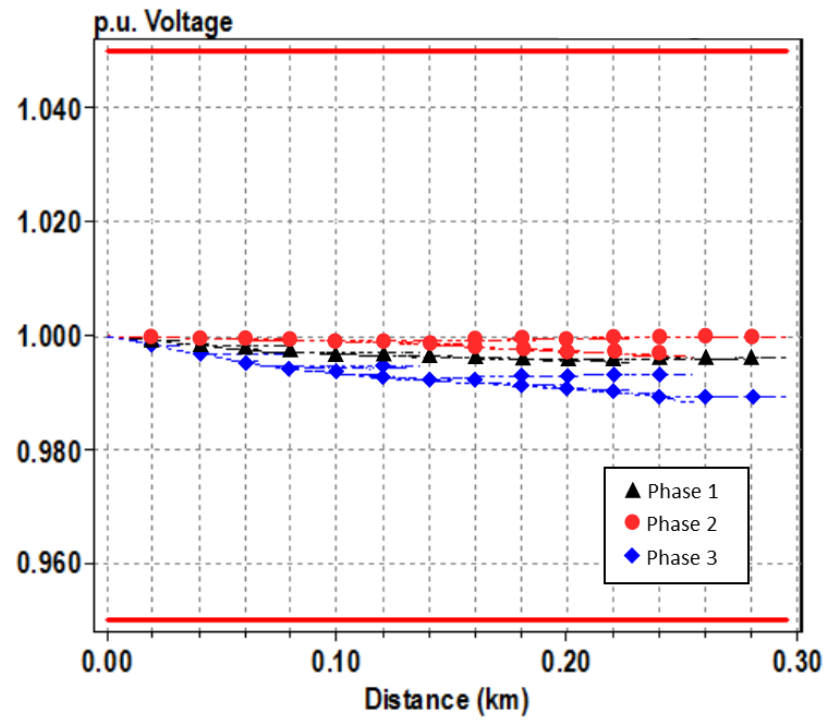

Figure 4: The three phase per unit voltage plotted against distance from the substation for the feeder. This is the base case voltage profile.

Figure 4 shows the base case voltage profile for the feeder system without any embedded solar generation. There is no voltage rise and the phases have remained well balanced.

\subsection{0\% PV Penetration without Storage - Case 1}

When the PV penetration reaches $20 \%$ the maximum export power becomes greater than the maximum input power for the feeder. This can be seen through the simple calculation showing the maximum PV generation at this penetration level is 11 $\times 4 \mathrm{kWp}=44 \mathrm{kWp}$. As such, under high solar irradiance conditions the export power is likely to have a greater value than the corresponding import peak power. Thus, the risk of overheating and subsequent failure for the components of the local distribution network is substantially increased due to higher levels of demand than those designed for.

Figure 5 shows the voltage variation in the feeder system for a period of high solar irradiance where solar panels were operating at very close to maximum power. A $3 \%$ voltage rise can be seen at a distance of $300 \mathrm{~m}$ from the substation on phase 1 , with a $1 \%$ voltage drop on phase 2 . This is due to differing number of PV installations on each phase. A maximum voltage unbalance ratio of $0.577 \%$ is observed in this scenario, this is 


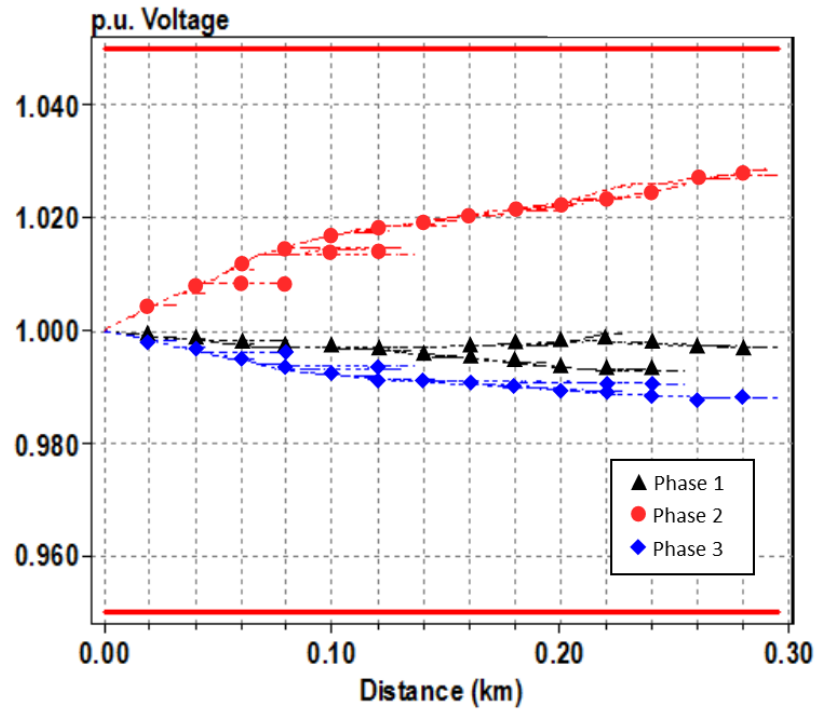

Figure 5: The three phase per unit voltage plotted against distance from the substation for the feeder with $20 \%$ PV penetration and either no storage or a feeder connected battery (subject to it being located at the sub-station).

quite low due to the unity power factor of the modeled PV panels. However, as the average feeder length in the UK is $1.5 \mathrm{~km}$ a higher level of voltage unbalance would be expected for a normal feeder under the same conditions due to the lower overall cable impedance seen in this example.

\section{2. $20 \%$ PV Penetration with Domestic Energy Storage - Case 2}

In the case of installed domestic batteries, the battery charges whilst the domestic generation exceeds demand and discharges while demand exceeds generation. This dispatch strategy leads to an unpredictable grid connection power profile, where the energy imported or exported depends entirely on the power balance within the home at any moment, regardless of the state of the wider grid at the time.

During periods of high solar irradiance the model shows that the domestic battery does not fully discharge between days, this is due to higher levels of electricity generation from the solar panels than the homes' demand. As such, even with very large capacity batteries, the home will need to export solar power at some point in the day when the battery becomes fully charged. Very little feeder demand peak reduction is therefore enabled by the inclusion of domestic batteries. Such domestic batteries can only remove load from the home they are connected to and as such, the percentage of peak load which can be shed is dependent on the PV penetration. This is seen by the modest reduction in peak load in Figure 6. In addition, demand reduction occurs through the night, i.e. during very low load conditions. It can be seen that, for these reasons, the utilisation of the energy storage capacity introduced with domestic batteries is very poor with relation to alleviating distribution system power flow issues due to the non-ideal dispatch times caused by reacting solely to the individual domestic loads.

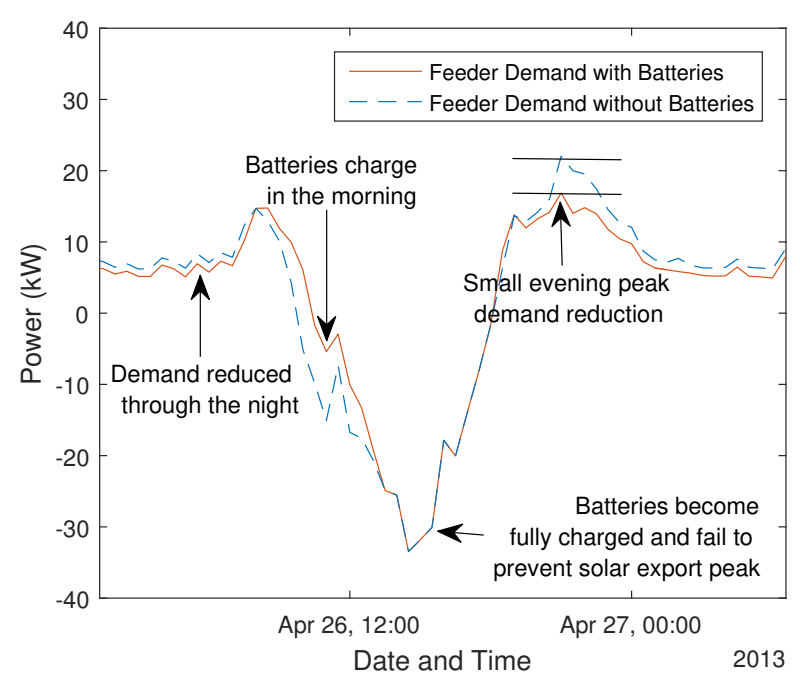

Figure 6: Typical feeder load profile with $11 \times 7 \mathrm{kWh}$ domestic batteries for a day having high solar irradiation levels.

When solar irradiance levels are low, the domestic battery utilisation levels fall. It can be shown that low solar irradiance levels lead to a small difference between the power profile with and without PV power. As such, there is very little energy available to charge the domestic batteries. Hence, although there is still a high level of energy storage capacity on the feeder system, it cannot be utilised to reduce the high peak powers which occur through the winter. However, since the state of charge of the domestic batteries is generally lower during periods of low solar irradiance, the batteries are available to absorb more solar power when it becomes available and as such, the export peaks during periods of low solar irradiance are more effectively reduced. This is shown in Figure 7

The voltage variation along the feeder system, as shown in Figure 8, is more balanced than without the domestic batteries for the instance shown and corresponds to a maximum voltage unbalance of $0.401 \%$. Since the domestic batteries are directly charged by the solar panels they are very effective at mitigating LV network voltage unbalance whilst they are charging. However, as discussed previously, during periods of high solar irradiance, the batteries will become fully charged early in the day. Due to the wide levels of acceptable voltage unbalance $(+10 \%$, $-6 \%$ ) on LV networks, voltage balancing effects on these are not of critical importance. Lower losses are seen on the LV network for the domestic battery case due to lower average power flows.

\section{3. $20 \%$ PV Penetration with Feeder Connected Storage - Case 3}

A feeder connected battery is able to respond directly to the aggregate feeder power flow data. In this way it is able to provide useful services such as valley filling and peak shaving. It can be very effective at doing this due to the data available to the feeder energy storage dispatch algorithm.

The effectiveness of the feeder connected battery is heavily dependent on charge and discharge levels relative to the moving 


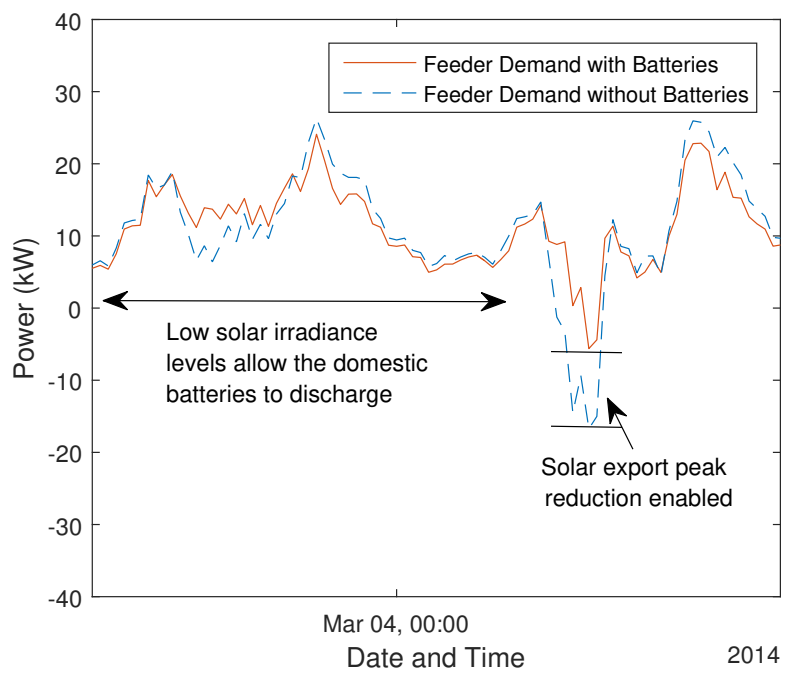

Figure 7: Typical feeder load profile with $11 \times 7 \mathrm{kWh}$ domestic batteries for a day having low solar irradiation levels.

average of the feeder demand. If the energy store is set to charge at a power level which is too high the battery will quickly become fully charged and then must allow a large export peak. Conversely if the battery is set to charge at a relatively low feeder demand, it will not be fully utilised and will not fully charge, reducing later peak demand reduction potential.

The choice of charge and discharge levels can be driven by either a desire to minimise exports from the feeder system or to minimise peak feeder demand. For the purposes of this study equal charge and discharge factors were set at the moving average for the past day $\pm 0.75 \times$ the moving standard deviation for the past day. For optimal results the shape of the demand profile must be considered such that an equal charge and discharge energy is selected for each day, in this way battery saturation can be prevented.

For days of high solar irradiance the feeder battery is able to smooth the peaks of the feeder load and reduce the exports, as shown in Figure 9, in this example the peak export power is reduced by $15 \mathrm{~kW}$ due to the battery. With a PV penetration of $20 \%$ the mean power is negative for days of high solar irradiance, i.e. the solar panels are generating more electrical energy than the feeder inhabitants are using. In this case there must be an export of electrical energy unless very high capacity seasonal storage is implemented. As such, the charge level for the battery is at $-15 \mathrm{~kW}$, in this way the battery does not become fully charged before the peak export power.

When solar irradiance levels are low the feeder connected battery can still act to fill the valleys and shave the peaks. Figure 10 shows a preferential feeder demand compared to the domestic battery case since the export was completely prevented and greater reductions were made to the evening demand on both days in this figure. This shows that the dispatch strategy of the feeder connected battery allows for grid services at many states of weather and feeder demand and can reliably reduce the feeder export peak. In contrast, for domestic batteries to be

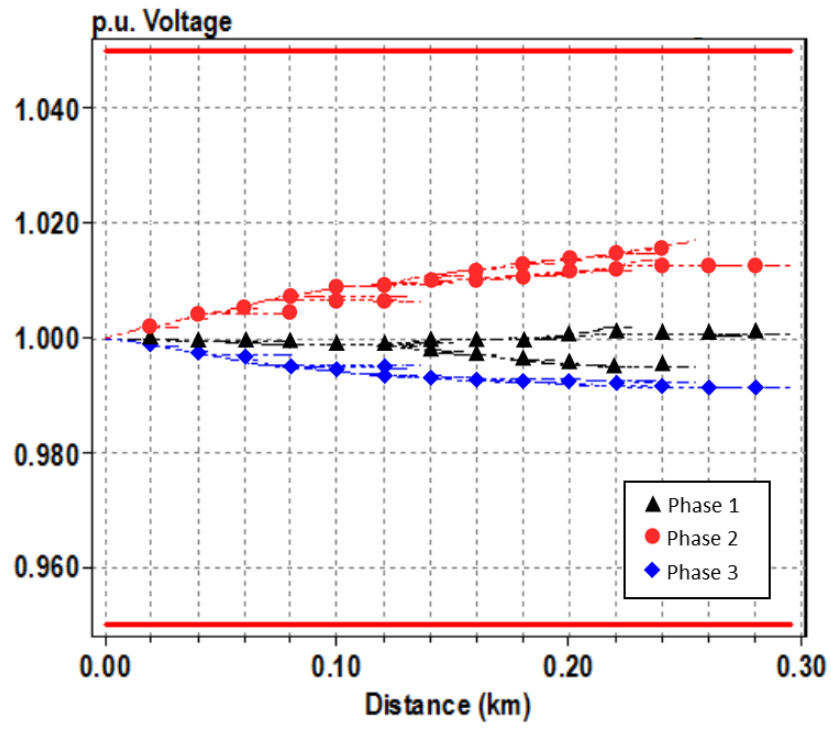

Figure 8: The three phase per unit voltage plotted against distance from the substation for the feeder with $20 \%$ PV penetration and $11 \times 7 \mathrm{kWh}$ domestic batteries.

effective with simple dispatch strategies, there must be a low average state of charge and high solar irradiance.

The voltage profile of the feeder system presented from the OpenDSS simulation is exactly the same for the feeder connected battery as the no storage case since there is no energy storage on the feeder system, as it is located at the substation. There is very little difference between the LV network line losses calculated for the feeder connected battery case and the no storage case, again due to the battery location. If the battery were located centrally within the feeder, the cable length between the battery and the PV panels would be decreased and as such lower losses would be seen.

\subsection{Export characteristics}

For both cases of battery installation, i.e. domestic versus feeder connected, a reduction in the total of the sum of energy exports from the feeder is evident. The reduction in exports is consistently higher for the feeder connected battery case and the benefit of feeder-connected batteries over domestic batteries grows for capacities over 70kWh. This is shown in Figure 11

The domestic battery case shows a plateau in exports where further increases above a battery capacity of $7 \mathrm{kWh}$ per home have a diminished ability to reduce exports. This is largely due to battery saturation, i.e. the home is producing more power than it is using and therefore the battery becomes fully charged and export must occur.

The export characteristics of the feeder-connected battery case are dependent on the charge and discharge levels set for the battery. In order to optimally reduce the peak export power the charge point must be further away from the moving average. However, for optimal export reduction over the course of the year it must be ensured that the full capacity of the battery is utilised for each solar peak. This is best achieved by setting the charge level close to the moving average. However, this 


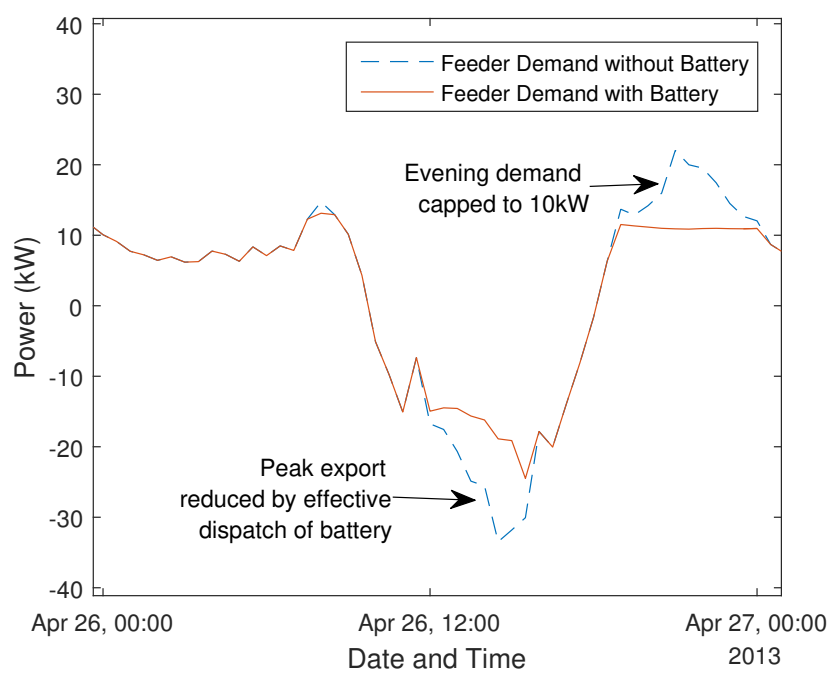

Figure 9: Typical feeder load profile with a $77 \mathrm{kWh}$ feeder connected battery for a day with high solar irradiation levels. Charge command for the battery is at dispatch factor 1.2.

leads to a much higher likelihood that the battery will be fully charged before the peak of solar irradiance and as such, peak export reduction capability is reduced. The plateau seen in the exports for the feeder-connected case in Figure 11 shows this point, where the charging point of the battery increases in order to ensure effective peak reduction, through control by Equation 5. however, the lack of inter-seasonal control due to the static nature of the dispatch factor in this simulation leads to some under-utilisation at high battery capacities. This is a result of the changing shape of the load leading to much larger export peak than import peaks during the summer due to the high solar power penetration levels. If the dispatch factor was dynamic and changed value effectively to account for this changing load shape, the export reduction would become directly proportional to battery capacity for a feeder connected battery.

For optimal control of the feeder-connected battery, the charging level should be set at the lowest possible power which will fully discharge the battery. Thus, both the export peak and the total exported energy are reduced by the maximum possible amount. These levels change throughout the year due to changing load shapes and as such a dynamic battery control algorithm is needed.

Figure 12 shows the variation in the mean of the daily moving minimum values for the domestic and feeder-connected battery cases plotted against the battery capacity. A sharp reduction is caused by introducing domestic batteries up to $5 \mathrm{kWh}$, but only small further reductions are seen as the battery size increases further. The feeder-connected battery does not reduce the peaks to the same extent as the domestic batteries at low capacities in this simulation. At higher capacities the feeder connected battery becomes much more effective with a $3.5 \mathrm{~kW}$ reduction in the average peak demand. The charge and discharge levels of the feeder connected battery does not change through this simulation and as such a low-capacity feeder con-

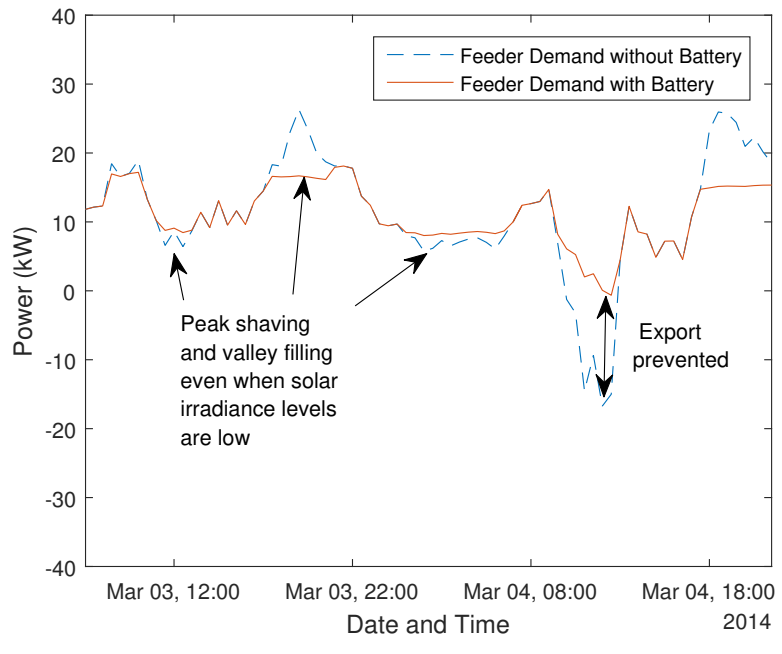

Figure 10: Typical feeder load profile with $77 \mathrm{kWh}$ feeder connected battery for a day low high solar irradiation levels. Charge command for the battery is at dispatch factor 0.75 .

nected battery is not optimised for peak reduction since it will become fully charged or discharged before the peak occurs, as such the battery is under-performing when measured using this metric. Since the domestic batteries can only mitigate the demand from the home in which they are situated there is an upper limit to demand reduction when the entire demand for the home is met by the combination of solar and batteries, this causes the plateau seen for domestic batteries above 50kWh $(4.5 \mathrm{kWh} \times 11$ homes).

The daily moving minimum of the feeder demand for varying battery capacities is shown in Figure 13 This clearly shows that in both cases, the addition of energy storage leads to an decrease of the maximum export power. It can be seen that as the battery size increases for both the domestic and feeder connected cases the moving minimum mean follows an ' $S$ ' shape, with most increases coming for battery sizes between $30-100 \mathrm{kWh}$ However, as the size of the batteries increases beyond $100 \mathrm{kWh}$ there are diminishing returns in both cases. The feeder connected battery reduces the maximum export power more than the domestic batteries at all points in this simulation. There is no scope for the domestic batteries to further reduce export power if they only react to the domestic load profile. However, the dispatch of the feeder connected battery is not optimal in this case, since the same dispatch parameter was used for the entire simulation. Thus, further reductions could be made to the moving minimum mean of the feeder connected battery case presented here.

\section{Conclusions}

If net generation (from rooftop solar) exceeds net demand for a domestic house, energy export from that house will always occur when using the control strategies outlined in this paper, regardless of the battery size, due to saturation of the battery. However, feeder connected batteries can be targeted in dispatch 


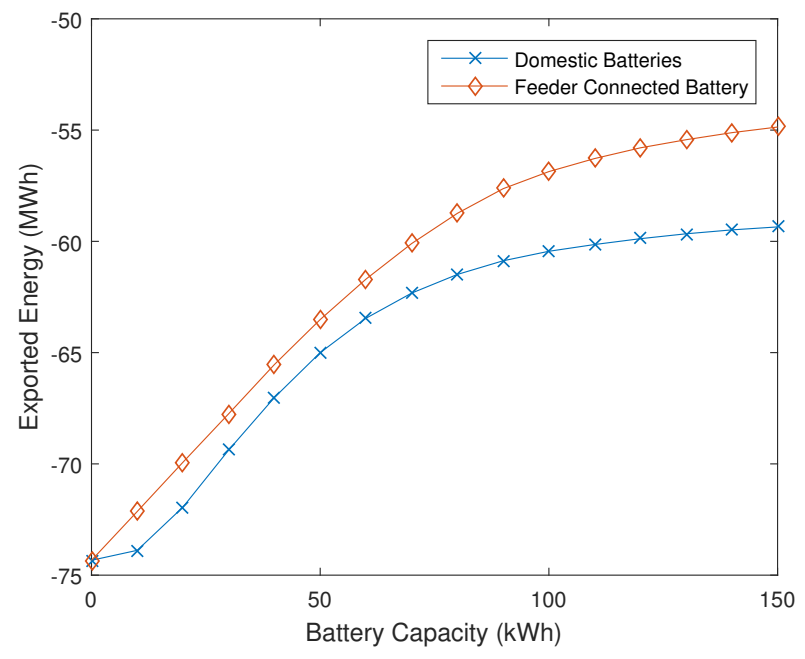

Figure 11: Export characteristics of domestic and feeder batteries plotted against battery size for the feeder with $20 \%$ PV penetration, i.e. $11 \mathrm{x} 4 \mathrm{kWp}$ PV arrays. Dispatch of the feeder connected battery occurs at dispatch factor 0.75 .

through control in their dispatch strategies and this leads to a greater reduction in exports.

Feeder connected battery peak shifting is successful since peaks at this level of the grid are pronounced, easily predicted and easily mitigated. Increased capacity showed a plateau behavior for reducing peaks, however, this was due to the simplicity of the dispatch algorithm. Charge and discharge points must be dynamically controlled in order to achieve best results. Peak shaving was not as successful with domestic batteries, only the demand of the home with the battery can be removed and load reduction goes through the night, when it is least needed. Domestic batteries can be effective at valley filling due to the exposure to larger energy flows of the PV array.

Voltage violations on the LV network are more likely with feeder connected batteries. A focus on the battery connection method and location would improve this, a connection between each phase and central battery placement would lead to improved LV network voltage performance. A mixed effect of the domestic batteries on voltage violation was seen, when the battery is charging the positive effect on the LV network is profound due to complete absorption of the solar energy. However, during the summer months the battery would become fully charged in the afternoon, leaving no protection from voltage violations. A data connection utilising forecasting will alleviate these problems for domestic batteries, however, it is likely that under current incentives these measures will be resisted by the battery owners due to concerns over reduction in selfconsumption.

Domestic batteries may be much easier to implement, and customers are much more willing to install them. As such the effects of them are likely to become a reality. In this case a hybrid energy storage approach should be implemented which uses feeder-connected batteries to mitigate the effects of those in a domestic setting.

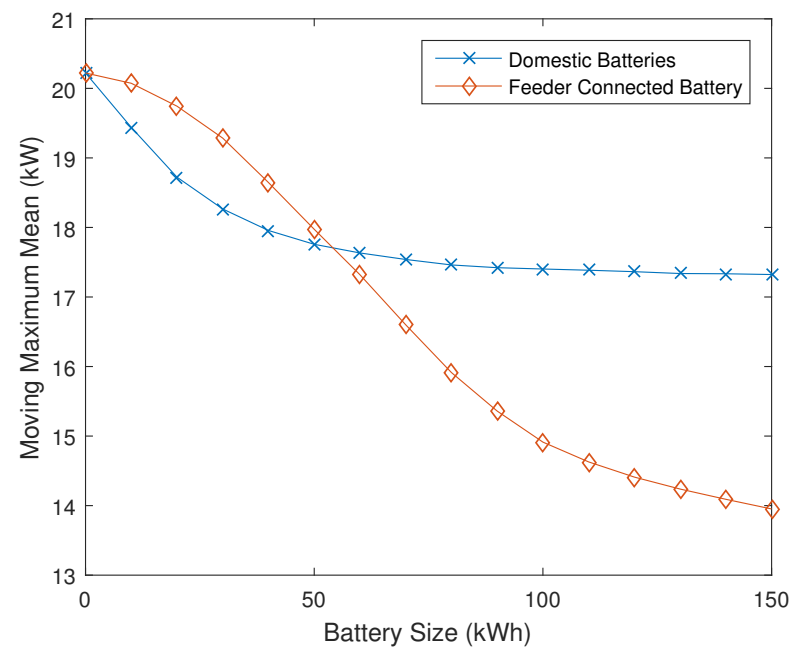

Figure 12: Moving maximum mean characteristics of domestic and feeder batteries plotted against battery size for the feeder with $20 \% \mathrm{PV}$ penetration, i.e. 11 $\mathrm{x} 4 \mathrm{kWp}$ PV arrays. Dispatch of the feeder connected battery occurs at dispatch factor 0.75 .

\section{Acknowledgments and Data Availability}

The authors would like to thank the UK Engineering and Physical Science Research Council (EPSRC) for funding this work through the Centre for Doctoral Training (CDT) in Energy Storage and its Applications (EP/L016818/1).

In addition, the authors would like to thank the Newquay Weather Station for providing solar irradiance and power generation data, and the Thames Valley Vision Project for providing domestic load data.

All other data and models supporting this study are openly available from the University of Southampton repository at http://doi.org/10.5258/SOTON/D0166.

[1] Climate Change Act 2008. Available online at http://www . legislation.gov.uk/ukpga/2008/27/

[2] Department of Energy and Climate Change. Renewable energy sources. In Digest of United Kingdom Energy Statistics (DUKES) 2015, pages 157-196. 2015. Available online at https://www.gov.uk/government/uploads/system/uploads/ attachment_data/file/450302/DUKES_2015.pdf

[3] Ian Richardson, Murray Thomson, David Infield, and Conor Clifford. Domestic electricity use: A high-resolution energy demand model. Energy and Buildings, 42(10):1878-1887, October 2010. Available online at http://wwW. sciencedirect.com/science/article/ pii/S0378778810001854

[4] Daniel Noll, Colleen Dawes, and Varun Rai. Solar Community Organizations and active peer effects in the adoption of residential PV. Energy Policy, 67:330-343, April 2014. Available online at http://www . sciencedirect.com/science/article/pii/SQ301421513013141

[5] Marco Bortolini, Mauro Gamberi, and Alessandro Graziani. Technical and economic design of photovoltaic and battery energy storage system. Energy Conversion and Management, 86:81 - 92, 2014.

[6] Solar photovoltaics deployment - publications - gov.uk. Available online at https://www.gov.uk/government/statistics/ solar-photovoltaics-deployment

[7] M. Thomson and D.G. Infield. Impact of widespread photovoltaics generation on distribution systems. Renewable Power Generation, IET, 1(1):33-40, March 2007.

[8] Energy Network Association. The Distribution Code of Licensed Dis- 


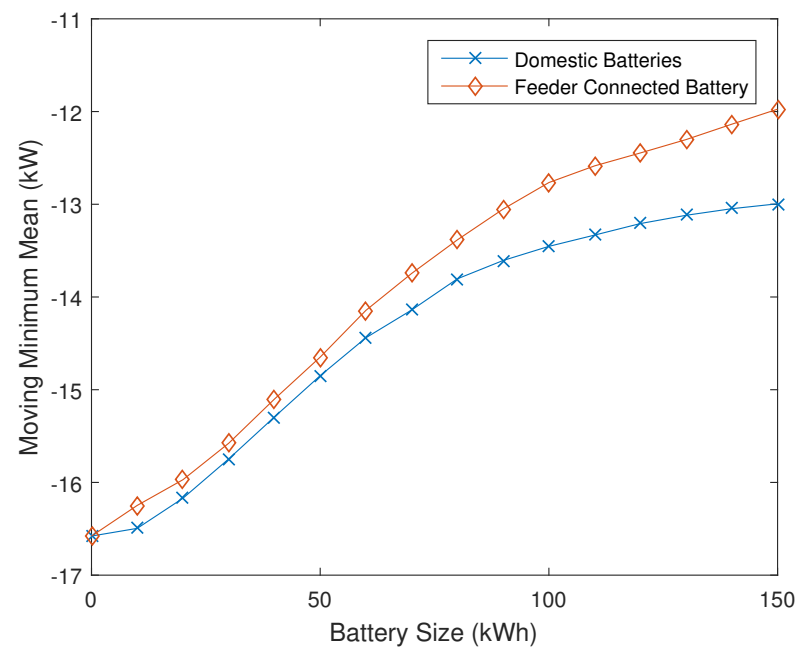

Figure 13: Moving minimum mean characteristics of domestic and feeder batteries plotted against battery size for the feeder with $20 \% \mathrm{PV}$ penetration, i.e. 11 $\mathrm{x} 4 \mathrm{kWp}$ PV arrays. Dispatch of the feeder connected battery occurs at dispatch factor 0.75 .

tribution Network Operators. (25), 2014. Available online at http: //www.energynetworks.org/

[9] Quality of Service Guaranteed Standards | Ofgem. Available online at https://www.ofgem.gov.uk/licences-codes-and-standards/ standards/quality-service-guaranteed-standards

[10] S Conti, S Raiti, and G Tina. Small-scale embedded generation effect on voltage profile: an analytical method. IEE Proceedings-Generation, Transmission and Distribution, 150(1):78-86, 2003.

[11] Farhad Shahnia, Ritwik Majumder, Arindam Ghosh, Gerard Ledwich, and Firuz Zare. Voltage imbalance analysis in residential low voltage distribution networks with rooftop pvs. Electric Power Systems Research, 81(9):1805 - 1814, 2011

[12] The Electricity Council. Planning limits for voltage unbalance in the united kingdom. Engineering Reccomendation P29, 1990. Available online at http://www . energynetworks .org/

[13] Kevin Lee, Giri Venkataramanan, and Thomas M. Jahns. Source current harmonic analysis of adjustable speed drives under input voltage unbalance and sag conditions. IEEE Transactions on Power Delivery, 21(2):567-576, 2006

[14] P. Trichakis, P.C. Taylor, P.F. Lyons, and R. Hair. Predicting the technical impacts of high levels of small-scale embedded generators on low-voltage networks. Renewable Power Generation, IET, 2(4):249-262, December 2008.

[15] P Pillay and M Manyage. Definitions of Voltage Unbalance. IEEE Power Engineering Review, (May):50-51, 2001.

[16] I.A. Metwally. Failures, monitoring and new trends of power transformers. Potentials, IEEE, 30(3):36-43, May 2011

[17] Raji Murugan and Raju Ramasamy. Failure analysis of power transformer for effective maintenance planning in electric utilities. Engineering Failure Analysis, 55:182 - 192, 2015.

[18] José Antonio Jardini, José Luiz Pereira Brittes, Luiz Carlos Magrini, Marco a. Bini, and Jorge Yasuoka. Power transformer temperature evaluation for overloading conditions. IEEE Transactions on Power Delivery, 20(1):179-184, 2005.

[19] Mark Smith. Specification for Planning \& Design of Greenfield Low Voltage Housing Estates. Scottish and Southern Energy, 2003.

[20] Ofgem. Feed-in tariff generation and export payment rate table for photovoltaic installations - feed in tariff year 7 (2016/17). 2016. Available online at https://wWw.ofgem.gov.uk/system/files/docs/2016/ 02/feed_in_tariff_scheme_tariff_table_1_april_2016_31_ march_2017_pv_only.pdf

[21] D.P. Jenkins, J. Fletcher, and D. Kane. Model for evaluating impact of battery storage on microgeneration systems in dwellings. En- ergy Conversion and Management, 49(8):2413 - 2424, 2008. Available online at http://www.sciencedirect.com/science/article/ pii/S0196890408000241

[22] Prasenjit Basak, S. Chowdhury, S. Halder nee Dey, and S.P. Chowdhury. A literature review on integration of distributed energy resources in the perspective of control, protection and stability of microgrid. Renewable and Sustainable Energy Reviews, 16(8):5545 - 5556, 2012. Available online at http://www . sciencedirect. com/science/article/ pii/S1364032112003772

[23] Tesla Powerwall. Available online at http://www.teslamotors.com/ en_GB/powerwall

[24] KfW presents Energy Turnaround Action Plan Financing offers support German Federal Govern-ment in transforming energy supply system. Available online at https://wWw.kfw. de/KfW-Group/Newsroom/Aktuelles/Pressemitteilungen/ Pressemitteilungen-Details_10957.html

[25] Mark Fulton, Reid Capalino, and J Auer. The German feed-in tariff: recent policy changes. Deutsche Bank Group, (September 2012):1-27, 2012. Available online at http://scholar.google.com/scholar? hl=en\&btnG=Search\&q=intitle: The+German+Feed-in+Tariff+: +Recent+Policy+Changes\#9

[26] AGORA Energiewende. 12 Insights on Germanys Energiewende. (February), 2013.

[27] Alexander Zeh and Rolf Witzmann. Operational strategies for battery storage systems in low-voltage distribution grids to limit the feed-in power of roof-mounted solar power systems. Energy Procedia, 46:114 - 123, 2014. 8th International Renewable Energy Storage Conference and Exhibition (IRES 2013).

[28] Francesco Marra, Guangya Yang, Chresten Trae Holt, Jacob Stergaard, and Esben Larsen. A decentralized storage strategy for residential feeders with photovoltaics. IEEE Transactions on Smart Grid, 5(2):974-981, 2014.

[29] Elke Lorenz, Johannes Hurka, Detlev Heinemann, and Hans Georg Beyer. Irradiance forecasting for the power prediction of grid-connected photovoltaic systems. Selected Topics in Applied Earth Observations and Remote Sensing, IEEE Journal of, 2(1):2-10, 2009.

[30] J. Cappelle, J. Vanalme, S. Vispoel, T. Van Maerhem, B. Verhelst, C. Debruyne, and J. Desmet. Introducing small storage capacity at residential pv installations to prevent overvoltages. In Smart Grid Communications (SmartGridComm), 2011 IEEE International Conference on, pages 534539, Oct 2011.

[31] MJE Alam, KM Muttaqi, and Darmawan Sutanto. Distributed energy storage for mitigation of voltage-rise impact caused by rooftop solar pv. In Power and Energy Society General Meeting, 2012 IEEE, pages 1-8. IEEE, 2012.

[32] Surendra Kaushik. Early learning report, 2014. Available online at http://wwW. westernpowerinnovation.co.uk/Document-library/2014/ Sola-Bristol-Operational-early-learning-report-fin. aspx

[33] Western Power Distribution. SoLa Bristol - Final Report. 2016. Available online at http://www.westernpowerinnovation.co.uk/ Documents/SoLa-Bristol.aspx

[34] Michiel Houwing, Petra Heijnen, and Ivo Bouwmans. Socio-technical complexity in energy infrastructures conceptual framework to study the impact of domestic level energy generation, storage and exchange. In Systems, Man and Cybernetics, 2006. SMC'06. IEEE International Conference on, volume 2, pages 906-911. IEEE, 2006.

[35] Alexandre Oudalov, Rachid Cherkaoui, and Antoine Beguin. Sizing and optimal operation of battery energy storage system for peak shaving application. In Power Tech, 2007 IEEE Lausanne, pages 621-625. IEEE, 2007.

[36] M. Zillmann, Ruifeng Yan, and T.K. Saha. Regulation of distribution network voltage using dispersed battery storage systems: A case study of a rural network. In Power and Energy Society General Meeting, 2011 IEEE, pages 1-8, July 2011.

[37] M.N. Kabir, Y. Mishra, G. Ledwich, Z.Y. Dong, and K.P. Wong. Coordinated control of grid-connected photovoltaic reactive power and battery energy storage systems to improve the voltage profile of a reoisidential distribution feeder. Industrial Informatics, IEEE Transactions on, 10(2):967-977, May 2014. 
[38] K.H. Chua, Yun Seng Lim, Phil Taylor, S. Morris, and Jianhui Wong. Energy storage system for mitigating voltage unbalance on low-voltage networks with photovoltaic systems. Power Delivery, IEEE Transactions on, 27(4):1783-1790, Oct 2012.

[39] Hedayat Saboori, Reza Hemmati, and Vahid Abbasi. Multistage distribution network expansion planning considering the emerging energy storage systems. Energy Conversion and Management, 105:938 - 945, 2015.

[40] Gideon Evans. LCNF Tier 1 Close-Down Report Demonstrating the Benefits of Monitoring LV Networks with embedded PV Panels and EV Charging Point. pages 1-74, 2013. Available online at https://www.ofgem.gov.uk/ofgem-publications/45826/ sset1002-lv-monitoring-lcnf-t1-close-down-report-130228. pdf

[41] Alistair Steele. LCNF Tier 1 Closedown Report Low Voltage Connected Energy Storage Document Owner ( s ). pages 1-80, 2014. Available online at https://www.ofgem.gov.uk/sites/default/files/ docs/2014/08/sset1008_lv_connected_batteries_closedown_ 2nd_submission_0.pdf

[42] G.K. Ari and Y. Baghzouz. Impact of high pv penetration on voltage regulation in electrical distribution systems. In Clean Electrical Power (ICCEP), 2011 International Conference on, pages 744-748, June 2011.

[43] Roger C Dugan. The Open Distribution System Simulator ( OpenDSS ). Electric Power Research Institute, Inc., (November):1-177, 2012. Available online at http://smartgrid.epri.com/SimulationTool. aspx

[44] Thames Valley Vision. Available online at http://www. thamesvalleyvision.co.uk/ 